\title{
Estimate of de novo mutation frequency in probands with PTEN hamartoma tumor syndrome
}

\author{
Jessica Mester, MS ${ }^{1}$ and Charis Eng, MD, $\mathrm{PhD}^{1}$
}

Purpose: PTEN hamartoma tumor syndrome is an autosomal dominant disorder with increased risks of neoplasias, macrocephaly, and developmental disabilities. While both familial and sporadic cases exist, actual de novo mutation frequency remains unknown. We sought to estimate this within our PTEN-mutation positive patient series.

Methods: Patients were prospectively accrued if they had known pathogenic germline PTEN mutations or phenotypic features suspicious for PHTS. Only families with pathogenic PTEN mutations were included. Likelihood for de novo mutation was graded from 1 (confirmed inherited) to 5 (confirmed de novo) based on family history and mutation status. Fisher's two-tailed exact and unpaired $t$-tests were used to compare between groups.

Results: 187 pathogenic PTEN-mutation positive families were eligible for this study. De novo (grade 5) status was confirmed in
$20(10.7 \%)$ probands, and in $36(19.3 \%)$ was suspected based on family history. Demographics, mutations, and phenotypes were similar for probands graded 1 vs. 5 (all $P>0.06$ ). In grade 1 probands, mutations were inherited equally from maternal and paternal lineages $(P=0.55)$.

Conclusions: The frequency of de novo PTEN mutation is at minimum $10.7 \%$ and at best $47.6 \%$. Absence of PHTS features within a family history should not preclude consideration of this diagnosis for patients with relevant personal history.

Genet Med 2012:14(9):819-822

Key Words: Bannayan-Riley-Ruvalcaba syndrome; Cowden syndrome; de novo mutation; germline PTEN mutation; inherited cancer syndrome

\section{INTRODUCTION}

PTEN hamartoma tumor syndrome (PHTS) is an umbrella term used to describe patients with variable phenotypes, most often Cowden syndrome (CS, OMIM \#158350) or BannayanRiley-Ruvalcaba syndrome (BRRS, OMIM \#153480), and germline mutation of the PTEN tumor suppressor gene. ${ }^{1,2}$ Patients with PHTS are at increased risk for breast, epithelial thyroid, endometrial, renal, and colorectal cancers, ${ }^{3,4}$ making timely diagnosis and identification of at-risk relatives critical for risk management. Both familial and apparently sporadic cases have been reported, ${ }^{2,5-7}$ however, the frequency of patients with $d e$ novo vs. inherited mutations has yet to be established as it has for other autosomal dominant conditions. ${ }^{8-10}$ We therefore sought to estimate the relative frequencies of de novo and inherited mutations in PHTS patients via review of family history data from our PTEN-mutation positive patient series.

\section{MATERIALS AND METHODS}

Patients were prospectively recruited after providing informed consent for Cleveland Clinic IRB\# 8458-PTEN substudy who presented with the following: relaxed International Cowden Consortium (ICC) criteria (meaning full diagnostic criteria ${ }^{11}$ minus one feature); macrocephaly plus autism/developmental delay/mental retardation; penile freckling; or presence of a known germline PTEN mutation. Germline PTEN mutation analysis was performed per Eng lab protocols as described elsewhere. ${ }^{3}$ Only families with probands found to have pathogenic PTEN mutations were eligible for this de novo mutation study.

Clinical data and family history information were requested and reviewed for all research participants, with special attention paid to documentation of clinical testing in family members. A five-tiered family history grading system was created to denote the degree of confidence regarding de novo mutation status in the proband (Table 1). A grade of 5 indicated that the mutation was molecularly proven to have occurred de novo. In other words, a PTEN mutation positive proband with both parents shown not to carry the same mutation received a grade of 5. A grade of 1 indicated that the mutation was molecularly proven to be inherited from a parent or, in the case in which one or both parents were deceased, was shared with a sibling. For cases in which family members had not undergone molecular testing, inheritance was judged as suspected inherited (grade 2) if the proband had a first-degree relative who met the ICC operational criteria for the diagnosis of CS in a family member. ${ }^{11}$ A grade of 3 was given when inheritance could not be predicted because of limited family structure and no first-degree relative met 
the ICC operational criteria for the diagnosis of CS in a family member. Family structure was judged as limited if at least one of the following were met: fewer than two women in either the maternal or paternal lineage survived beyond 50 years; ${ }^{12}$ one parent is either an only child or no information was recorded about aunts or uncles; or limited family history information was available for either lineage because of adoptive status or lack of contact. A grade of 4 was assigned when the mutation was suspected de novo, family structure was sufficient for analysis, and the proband had no first- or second-degree relatives (excluding descendants) meeting the ICC operational criteria for the diagnosis of CS in a family member. Reports of macrocephaly that were not confirmed by documented occipital-frontal circumference measurement were disregarded. Differences between groups were assessed with Fisher's two-tailed exact test and unpaired $t$-test, and $P<0.05$ was considered significant.

\section{RESULTS}

Among the 3,477 individuals accrued to the main 8458-PTEN study, 225 individuals belonging to 187 unrelated families were found to have clearly pathogenic germline PTEN mutations. Twenty mutations were confirmed as de novo through familial testing (grade 5) by the Eng research laboratory or testing in a CLIA-certified facility, leading to a conservatively calculated de novo mutation frequency of $10.7 \%(20 / 187)$ within all eligible families. If analysis is restricted to only those probands with known familial testing results (grade 1 and 5 probands, $n=42$ ), a maximum de novo mutation frequency of $47.6 \%(20 / 42)$ is obtained. Combining probands with confirmed (grade 5; Table 1) and suspected de novo

\begin{tabular}{|c|c|c|}
\hline Grade & $\begin{array}{l}\text { Number of } \\
\text { probands }\end{array}$ & Description \\
\hline 1 & 22 & $\begin{array}{l}\text { Proband mutation proven to be inherited by } \\
\text { molecular testing }\end{array}$ \\
\hline 2 & 48 & $\begin{array}{l}\text { No familial molecular testing performed; strong } \\
\text { suspicion for inherited mutation based on } \\
\text { presence of first-degree relative meeting } \\
\text { ICC operational criteria for CS diagnosis in a } \\
\text { family member }\end{array}$ \\
\hline 3 & 61 & $\begin{array}{l}\text { No familial molecular testing performed; unable } \\
\text { to predict if mutation de novo or inherited } \\
\text { because of lack of first-degree relatives meeting } \\
\text { ICC operational criteria for CS diagnosis in a } \\
\text { family member and limited family structure }\end{array}$ \\
\hline 4 & 36 & $\begin{array}{l}\text { No familial molecular testing performed; strong } \\
\text { suspicion for de novo mutation based on lack } \\
\text { of first- or second-degree relatives meeting ICC } \\
\text { operational criteria for CS diagnosis in a family } \\
\text { member with sufficient family structure for } \\
\text { analysis }\end{array}$ \\
\hline 5 & 20 & $\begin{array}{l}\text { Proband mutation proven to be de novo by } \\
\text { molecular testing }\end{array}$ \\
\hline
\end{tabular}

CS, Cowden syndrome; ICC, International Cowden Consortium. mutations (grade 4), a de novo mutation frequency of $29.9 \%$ $(56 / 187)$ is estimated.

Within the group molecularly proven to have de novo PTEN mutations (grade 5), features identified at presentation for testing were varied (Table 2). There were no differences in proportion of mutations that would lead to protein truncation vs. missense mutations $(P=0.51)$, gender $(P=0.55)$, or age at diagnosis $(P=0.12)$ between grade 1 vs. grade 5 probands. In grade 1 probands, mutations were inherited equally from the maternal and paternal lineages $(P=0.55)$. Within both groups, males were significantly younger at diagnosis than females $(P=0.002$ for both). Given that many PHTS features have gender- and age-related penetrance, ${ }^{7,13,14}$ grade 1 and grade 5 groups were stratified by gender to examine whether phenotypic differences were noted between patients; no such differences were found for any PHTS phenotype or for presence of any cancer diagnosis $(P>0.06$ for all phenotypes).

\section{DISCUSSION}

This study conservatively reveals at minimum a $10.7 \%$ de novo PTEN mutation frequency, and demonstrates at best a $47.6 \%$ de novo mutation frequency. This range may still be an underestimate given the possibility that patients without a striking family history may not be considered for referral to a genetics clinic for evaluation and testing. When PHTS is a part of the differential diagnosis, clinicians should be mindful of de novo mutation frequency and not exclude consideration of this syndrome for a patient who lacks relevant diagnoses in their family history.

We had posited that if present, an overrepresention of one mutation type or phenotype among patients with de novo vs. inherited mutations would imply that those de novo mutations led to an increased phenotypic severity, causing decrease in survival to age of reproduction or reproductive ability. We did not find evidence to support this hypothesis, and in fact found that when stratified by gender, patients with de novo mutations had no appreciable demographic, phenotypic, or genotypic differences from those with confirmed inherited mutations. This finding supports the need for all PHTS patients to adhere to screening guidelines, regardless of family history.

Approximately $60-90 \%$ of PTEN mutations are inherited. In some families in which a mutation was proven as inherited (grade 1), this result was not surprising given the number of other relatives in the family with relevant diagnoses. However, in other families, in particular when the proband was a young child, there was a lack of known relevant diagnoses in the family history; yet one parent, with no preference for maternal or paternal inheritance, was found to share the child's mutation. Given that many characteristics of PHTS have age-related penetrance, ${ }^{15,16}$ this was not an unexpected finding. Examining parents for phenotypic features suspicious for PHTS may help caregivers to predict which parent is more likely to test positive, so that parental testing can be performed in a step-wise and cost-saving manner. Macrocephaly is present in over 94\% of persons 
with PHTS $^{17}$ and is easily assessed by head circumference measurement, making this characteristic a potentially helpful and simple predictor of familial mutation status. Finding that most mutations are likely to be inherited is an important point to discuss with patients, and may increase their motivation to share their mutation status with at-risk family members so that predictive testing of relatives may be facilitated, enabling those testing positive to receive appropriate risk management.

We acknowledge the limitations inherent in this study, most notably the lack of medical record documentation for the majority of family members, for whom medical records could not be obtained if they were not study enrollees in accordance with our center's Institutional Review Board policies. We also regret that paternity testing was not possible given that in many situations, familial testing was performed through one of several clinical laboratories. Although we would have preferred to confirm the accuracy of the reported familial diagnoses and relationships, it may not be practical or possible in a clinical setting to do so, making the degree of diagnostic certainty in this study applicable to "real-life" clinical situations.

Our group has previously published a risk calculator, available online at http://www.lerner.ccf.org/gmi/ccscore/, that predicts the probability of having a germline PTEN mutation on the basis of personal medical history. ${ }^{3}$ Family history is a crucial component of risk assessment and testing criteria for many inherited cancer syndromes. ${ }^{18-22}$ We are currently studying family history diagnoses to determine which family history characteristics may be incorporated into a future version of this risk model.

Table 2 Clinical features of probands with de novo (grade 5) germline PTEN mutations

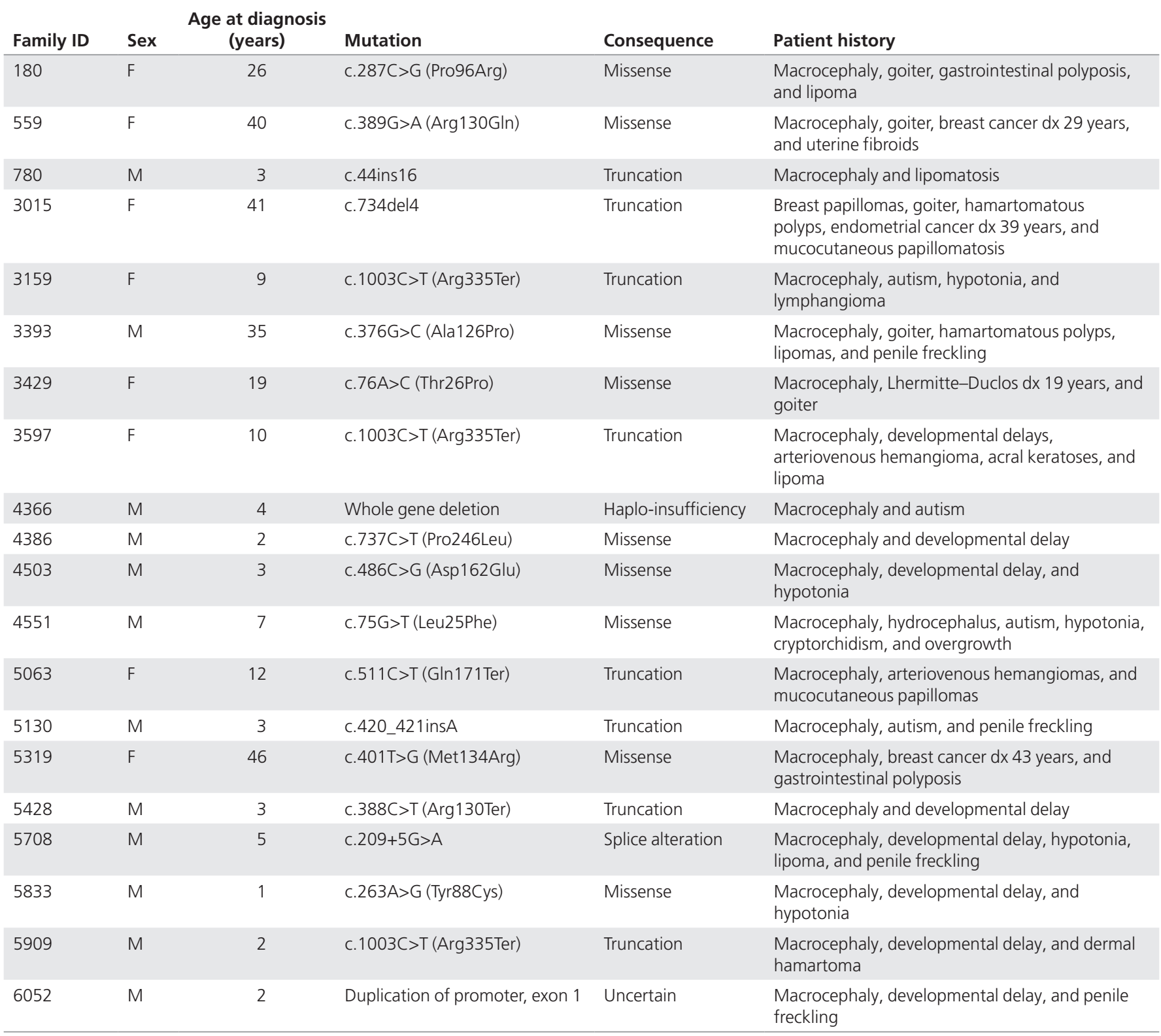




\section{ACKNOWLEDGMENTS}

The authors are grateful to the patients and their families who have taken part in this research over the past several years. The authors acknowledge all the genetic counselors, physicians, and other health-care providers who have referred patients to the study. This study was funded in part by R01CA118980 and P01CA124570 from the National Cancer Institute, the William Randolph Hearst Foundations, and the Healthnet Foundation (to C.E.). C.E. is the Sondra J. and Stephen R. Hardis Endowed Chair in Cancer Genomic Medicine at the Cleveland Clinic and is an American Cancer Society Clinical Research Professor, generously funded in part by the F.M. Kirby Foundation.

\section{DISCLOSURE}

The authors declare no conflict of interest.

\section{REFERENCES}

1. Zbuk KM, Eng C. Cancer phenomics: RET and PTEN as illustrative models. Nat Rev Cancer 2007;7:35-45.

2. Marsh DJ, Coulon V, Lunetta KL, et al. Mutation spectrum and genotypephenotype analyses in Cowden disease and Bannayan-Zonana syndrome, two hamartoma syndromes with germline PTEN mutation. Hum Mol Genet 1998;7:507-515.

3. Tan MH, Mester J, Peterson C, et al. A clinical scoring system for selection of patients for PTEN mutation testing is proposed on the basis of a prospective study of 3042 probands. Am J Hum Genet 2011;88:42-56.

4. Heald B, Mester J, Rybicki L, Orloff MS, Burke CA, Eng C. Frequent gastrointestinal polyps and colorectal adenocarcinomas in a prospective series of PTEN mutation carriers. Gastroenterology 2010;139:1927-1933.

5. Lynch ED, Ostermeyer EA, Lee MK, et al. Inherited mutations in PTEN that are associated with breast cancer, cowden disease, and juvenile polyposis. Am J Hum Genet 1997:61:1254-1260.

6. Marsh DJ, Kum JB, Lunetta KL, et al. PTEN mutation spectrum and genotype-phenotype correlations in Bannayan-Riley-Ruvalcaba syndrome suggest a single entity with Cowden syndrome. Hum Mol Genet 1999;8:1461-1472.

7. Tan MH, Mester JL, Ngeow J, Rybicki LA, Orloff MS, Eng C. Lifetime cancer risks in individuals with germline PTEN mutations. Clin Cancer Res 2012;18:400-407.
8. Shen MH, Harper PS, Upadhyaya M. Molecular genetics of neurofibromatosis type 1 (NF1). J Med Genet 1996;33:2-17.

9. Gray JR, Bridges $A B$, Faed MJ, et al. Ascertainment and severity of Marfan syndrome in a Scottish population. J Med Genet 1994;31: $51-54$.

10. Gonzalez KD, Buzin $\mathrm{CH}$, Noltner KA, et al. High frequency of de novo mutations in Li-Fraumeni syndrome. J Med Genet 2009;46: 689-693.

11. Pilarski R, Eng C. Will the real Cowden syndrome please stand up (again)? Expanding mutational and clinical spectra of the PTEN hamartoma tumour syndrome. J Med Genet 2004;41:323-326.

12. Weitzel JN, Lagos VI, Cullinane CA, et al. Limited family structure and BRCA gene mutation status in single cases of breast cancer. JAMA 2007:297:2587-2595.

13. Gorlin RJ, Cohen MM Jr, Condon LM, Burke BA. Bannayan-Riley-Ruvalcaba syndrome. Am J Med Genet 1992;44:307-314.

14. Lachlan KL, Lucassen AM, Bunyan D, Temple IK. Cowden syndrome and Bannayan Riley Ruvalcaba syndrome represent one condition with variable expression and age-related penetrance: results of a clinical study of PTEN mutation carriers. J Med Genet 2007;44:579-585.

15. Nelen MR, Padberg GW, Peeters EA, et al. Localization of the gene for Cowden disease to chromosome 10q22-23. Nat Genet 1996;13:114-116.

16. Eng C. Will the real Cowden syndrome please stand up: revised diagnostic criteria. J Med Genet 2000;37:828-830.

17. Mester JL, Tilot AK, Rybicki LA, Frazier TW II, Eng C. Analysis of prevalence and degree of macrocephaly in patients with germline PTEN mutations and of brain weight in Pten knock-in murine model. Eur J Hum Genet 2011;19:743-748

18. Vasen HF, Watson P, Mecklin JP, Lynch HT. New clinical criteria for hereditary nonpolyposis colorectal cancer (HNPCC, Lynch syndrome) proposed by the International Collaborative group on HNPCC. Gastroenterology 1999;116:1453-1456.

19. Parmigiani G, Berry D, Aguilar O. Determining carrier probabilities for breast cancer-susceptibility genes BRCA1 and BRCA2. Am J Hum Genet 1998;62:145-158.

20. Frank TS, Deffenbaugh AM, Reid JE, et al. Clinical characteristics of individuals with germline mutations in BRCA1 and BRCA2: analysis of 10,000 individuals. J Clin Oncol 2002;20:1480-1490.

21. Li FP, Fraumeni JF Jr, Mulvihill JJ, et al. A cancer family syndrome in twentyfour kindreds. Cancer Res 1988;48:5358-5362.

22. Fitzgerald RC, Hardwick R, Huntsman D, et al.; International Gastric Cancer Linkage Consortium. Hereditary diffuse gastric cancer: updated consensus guidelines for clinical management and directions for future research. J Med Genet 2010;47:436-444. 